\title{
Efficacy and safety of Tripterygium glycosides in Sjögren's syndrome treatment: evidence from 12 randomized controlled trials
}

\author{
Yue Luo ${ }^{1,2 \#}$, Ying Zhang ${ }^{1,2 \#}$, Le Kuai ${ }^{1,2}$, Meng Xing ${ }^{1,2}$, Yi Ru ${ }^{2}$, Ying Luo ${ }^{2}$, Liu Liu ${ }^{2}$, Jiale Chen ${ }^{1,2}$, Bin Li $^{1,3}$, \\ $\mathrm{Xin} \mathrm{Li}^{1,2}$ \\ ${ }^{1}$ Department of Dermatology, Yueyang Hospital of Integrated Traditional Chinese and Western Medicine, Shanghai University of Traditional \\ Chinese Medicine, Shanghai, China; ${ }^{2}$ Institute of Dermatology, Shanghai Academy of Traditional Chinese Medicine, Shanghai, China; ${ }^{3}$ Shanghai \\ Skin Disease Hospital, School of Medicine, Tongji University, Shanghai, China \\ Contributions: (I) Conception and design: X Li, B Li; (II) Administrative support: X Li, B Li; (III) Provision of study materials or patients: L Kuai, \\ M Xing; (IV) Collection and assembly of data: Y Ru, Ying L; (V) Data analysis and interpretation: Yue L, Y Zhang, L Liu, J Chen; (VI) Manuscript \\ writing: All authors; (VII) Final approval of manuscript: All authors. \\ \#These authors contributed equally to this work. \\ Correspondence to: Xin Li; Bin Li. Department of Dermatology, Yueyang Hospital of Integrated Traditional Chinese and Western Medicine, Shanghai \\ University of Traditional Chinese Medicine, Shanghai 200437, China. Email: 13661956326@163.com; 18930568129@163.com.
}

\begin{abstract}
Background: Tripterygium glycosides (TGs) has been widely used in the treatment of Sjögren's syndrome (SS). Methods: Seven databases, PubMed, Embase, Cochrane Library, China National Knowledge Infrastructure, Wanfang Medical Database, China Science and Technology Journal Database, and the Chinese Biomedicine database, were selected to collect randomized controlled trials (RCTs) related to the treatment of SS with TGs alone or in combination. The participants, intervention, comparison, outcome, and study design principle were adopted for the inclusion of related studies. The risk of bias was assessed using the Cochrane Collaboration's tool. Meta-analysis was conducted using RevMan 5.3, with risk ratios (RRs) or standard mean differences (SMDs) and 95\% confidence intervals (CIs).

Results: Overall, 12 trials involving 668 patients were analyzed. The results of the meta-analysis showed that TGs in combination with total glucosides of paeony (TGP) had significantly lower symptom scores than TGs alone on dry eyes (SMD =-0.61, 95\% CI: -1.12 to $-0.10, \mathrm{P}=0.02)$ or dry mouth $(\mathrm{SMD}=-1.29$, 95\% CI: -1.84 to $-0.74, \mathrm{P}<0.00001)$. The efficacy rates of TG + TGP vs. TGs $(\mathrm{P}<0.00001)$ and TG $+\mathrm{HM}$ vs. TGs $(\mathrm{P}=0.01)$ were significantly different. In addition, compared to hydroxychloroquine (HCQ), TGs could induce expression of $\mathrm{C}$-reactive protein $(\mathrm{P}=0.007)$, globulin $(\mathrm{P}<0.00001)$, and immunoglobulin $\mathrm{A}$ (IgA) $(\mathrm{P}=0.006)$, whereas the TG + TGP group had lower levels of immunoglobulin $\mathrm{G}(\mathrm{IgG})(\mathrm{P}<0.00001)$, immunoglobulin $M(\operatorname{IgM})(\mathrm{P}=0.02)$, and $\operatorname{IgA}(\mathrm{P}<0.00001)$, as well as saliva flow rate $(\mathrm{P}<0.00001)$ and lacrimal gland function $(\mathrm{P}<0.00001)$. The adverse events between TGs and HCQ were not evident, and there was no increase in the risk of adverse reactions when combined with other drugs.
\end{abstract}

Discussion: TGs are potentially effective for treating SS without increasing the risk of adverse events. High-quality, multi-center, and large-scale RCTs are required.

Keywords: Sjögren's syndrome (SS); Tripterygium glycosides (TGs); meta-analysis

Submitted Jan 29, 2021. Accepted for publication May 28, 2021.

doi: $10.21037 / \mathrm{apm}-21-256$

View this article at: https://dx.doi.org/10.21037/apm-21-256 


\section{Introduction}

Sjögren's syndrome (SS) is a chronic systemic autoimmune disease characterized by progressive exocrine gland damage (1), affecting $0.4 \%$ people in China (2) and $0.1-0.4 \%$ people in the UK (3). Patients with SS are categorized into having primary or secondary SS. Decreased function of the salivary and lacrimal glands commonly causes dry mouth and eyes. Furthermore, SS has been reported to cause multiple organ damage, including immune thrombocytopenia, interstitial lung disease, and a $5-10 \%$ lifetime risk of B-cell lymphoma (4). The histological characteristics of SS include focal lymphocytic infiltration of exocrine glands (5), with a plethora of autoantibodies, cryoglobulins, hypocomplementemia, and hypergammaglobulinemia present in the serum of patients $(6,7)$. Physical limitations and life-shortening complications (e.g., lymphoma) caused by SS result in a significant financial burden on the patient's family and healthcare services (8).

The etiology and pathogenesis of SS are not fully understood (5); therefore, therapeutic regimens are focused on symptom relief and broad-spectrum immunosuppression. According to the European League Against Rheumatism (EULAR) guidelines for SS (9), symptomatic treatments with of topical oral (e.g., saliva substitutes) and ocular (e.g., artificial tear drops) therapies only transiently relieve symptoms, which ultimately reoccur after therapeutic withdrawal. Furthermore, EULAR guidelines recommend immuno-directed therapies, such as hydroxychloroquine (HCQ) and oral glucocorticoids, as well as synthetic immunosuppressive and biologic agents, which have elevated incidences of serious adverse events (9). As such, efficacious and feasible interventions to treat SS, an orphan disease (10), are warranted.

In China, Tripterygium glycosides (TGs), extracted from Tripterygium wilfordii Hook F. of euonymus (11), are increasingly being used for the treatment of SS. TG, known as a "herbal hormone", is a fat-soluble mixture of active compounds, including diterpene lactones, alkaloids, and triterpenes, with bioactive and toxic constituents such as triptolide and celastrol $(12,13)$. TGs can elicit immunosuppressive, anti-inflammatory, and anticancer effects (14), and exhibit significant clinical therapeutic potential, as highlighted in systematic reviews (15-18). Furthermore, guidelines on rheumatoid arthritis (RA) from the China Association of Chinese Medicine (CACM) (19) and Royal Australian College of General Practitioners (RACGP) (20) state that T. wilfordii effectively relieves the symptoms of RA, whereas TGs have been more commonly used for the treatment of autoimmune or inflammatory diseases including systemic lupus erythematosus and SS (21). However, one of our previous reviews indicated that the toxic side effects and adverse events of TGs include hepatotoxicity, reproductive toxicity, nematotoxicity, and intestinal toxicity (17), which may limit their clinical application.

However, systematic reviews have shown that combination therapies using TGs may be used to increase potency without increasing the risk of adverse events (18), which will enhance rational drug use and promote clinical therapy using TGs. It has been reported that the clinical effectiveness rate is significantly higher while using TGs in combination with topical glucocorticoids than that while using topical glucocorticoids alone $(\mathrm{P}<0.00001)$; additionally, the combination did not increase the occurrence or severity of adverse reactions (15). After primary literature research, it was found that literature on SS treated with TGs alone is limited; thus, the present study provides evidence on combination therapies using TGs.

Therefore, a meta-analysis of randomized controlled trials (RCTs) was performed in the current study to assess the therapeutic effectiveness of using TGs alone and in combination, as well as the associated adverse events, in the treatment of SS. We present the following article in accordance with the PRISMA reporting checklist (available at https://dx.doi.org/10.21037/apm-21-256).

\section{Methods}

\section{The main components of TGs}

High-performance liquid chromatography (HPLC) analysis (22) was used to determine the main components of TGs (Lot No. 20160701), which included triptonide $(0.2451 \mathrm{mg} / \mathrm{g})$, triptolide $(0.0806 \mathrm{mg} / \mathrm{g})$, triptophenolide $(0.3645 \mathrm{mg} / \mathrm{g})$, celastrol $(0.2619 \mathrm{mg} / \mathrm{g})$, wilforine $(0.2941 \mathrm{mg} / \mathrm{g})$, and wilforlide A $(0.3557 \mathrm{mg} / \mathrm{g})$. The molecular structures of the main components of TGs are shown in Table S1.

\section{Procedures}

The procedures of the study followed a previously established protocol registered with PROSPERO (CRD42020185678), according to the Preferred Reporting Items for Systematic Reviews and Meta-analyses (PRISMA) guidelines (23). 
Table 1 Characteristics of the included studies on the efficacy and safety of Tripterygium glycosides in Sjögren's syndrome treatment

\begin{tabular}{|c|c|c|c|c|c|c|c|c|c|c|}
\hline \multirow[t]{2}{*}{ Study } & \multicolumn{2}{|c|}{$\begin{array}{l}\text { Sample } \\
\text { size }\end{array}$} & \multicolumn{2}{|c|}{$\begin{array}{l}\text { Patients } \\
\text { (M/F) }\end{array}$} & \multicolumn{2}{|c|}{$\begin{array}{l}\text { Average age } \\
\text { (years) }\end{array}$} & \multicolumn{2}{|c|}{$\begin{array}{l}\text { Average course duration } \\
\text { of disease (years) }\end{array}$} & \multicolumn{2}{|c|}{ Interventions } \\
\hline & $E$ & $\mathrm{C}$ & E & $\mathrm{C}$ & $E$ & $\mathrm{C}$ & $E$ & $\mathrm{C}$ & E & $\mathrm{C}$ \\
\hline Zhao 2019 & 42 & 42 & $18 / 24$ & $17 / 25$ & $51.52(6.22)$ & $50.53(6.24)$ & $6.51(1.54)$ & $5.52(1.56)$ & TGs + TGP & TGs \\
\hline Jiang 2018 & 35 & 35 & $7 / 28$ & $6 / 29$ & $45.21(6.07)$ & $45.32(6.11)$ & $4.06(2.17)$ & $3.97(2.06)$ & TGs + TGP & TGs \\
\hline Qiang 2018 & 37 & 38 & $3 / 35$ & $2 / 35$ & 51.95 (11.23) & $50.86(8.75)$ & $6.12(4.59)$ & $5.83(6.12)$ & TGs & $\begin{array}{l}\text { Huoxue Jiedu } \\
\text { Decoction }\end{array}$ \\
\hline Wang 2017 & 49 & 49 & $20 / 29$ & $18 / 31$ & $49.7(5.8)$ & $50.1(5.6)$ & NR & NR & TGs + TGP & TGs \\
\hline Ma 2012 & 22 & 22 & $1 / 21$ & $1 / 21$ & $50(7.14)$ & $51(7.82)$ & $19(6.46)$ & $18(6.72)$ & TGs & $\mathrm{HCQ}$ \\
\hline Guo 2012 & 15 & 15 & NR & NR & $51.9(7.1)$ & $52.3(7.2)$ & $3.9(5.7)$ & $3.4(5.8)$ & TGs & $\mathrm{HCQ}$ \\
\hline Cui 2012 & 18 & 17 & $1 / 16$ & $1 / 17$ & $59.39(10.98)$ & $60.60(10.07)$ & $8.51(6.54)$ & 7.44 (5.63) & TGs & $\begin{array}{l}\text { Huoxue Jiedu Yangyin } \\
\text { Shengjin Decoction }\end{array}$ \\
\hline Zhu 2010 & 31 & 32 & $2 / 30$ & $1 / 30$ & $52.00(10.37)$ & 51.06 (9.39) & $6.03(5.17)$ & $5.94(5.25)$ & TGs & $\begin{array}{l}\text { Huoxue Jiedu } \\
\text { Decoction }\end{array}$ \\
\hline
\end{tabular}

E, experimental group; C, control group; NR, not reported; RCT, randomized control trial; M, male; F, female; AEs, adverse events; TGs, Tripterygium glycosides; TGP, total glucosides of paeony; HCQ, hydroxychloroquine.

\section{Search trials}

Using the subject terms and free terms as search terms (Table S2), we systematically searched PubMed, Embase, Cochrane Library, China National Knowledge Infrastructure (CNKI), Wanfang Medical Database, China Science and Technology Journal Database (CQVIP), and the Chinese Biomedicine (CBM) database, from the start date to March 12, 2020. The language conditions for retrieving literature were English and Chinese.

\section{Study selection}

Subsequently, the title, abstract, and full text were screened to identify articles using the following inclusion criteria: RCTs including patients diagnosed with SS; the intervention groups including TGs alone or combined therapies; the control groups including raw Chinese herbal medicine (HM), Chinese patent medicine, or western medicine; reporting outcome data regardless of efficacy rate, symptom scores, serum index, or adverse events. The criteria were followed by participants, intervention, comparison, outcome, and study design (PICOS) principle, which is presented in the supplementary material (Table S3).

\section{Data extraction}

The two authors independently extracted data by reading the titles, abstracts, and full texts of the included studies. The characteristics of the included studies are summarized in Tables 1,2, including the year of publication, first author, location, sample size, age and sex of patients, average course duration of disease, interventions, dosage, course of treatment, adverse events, efficacy rate, symptom scores, serum index, and physical index.

\section{Risk of bias assessments}

Risk assessments were performed using Cochrane bias risk tools, including random sequence generation (selection bias), allocation concealment (selection bias), 
Table 2 Characteristics of the included studies on the efficacy and safety of Tripterygium glycosides in Sjögren's syndrome treatment

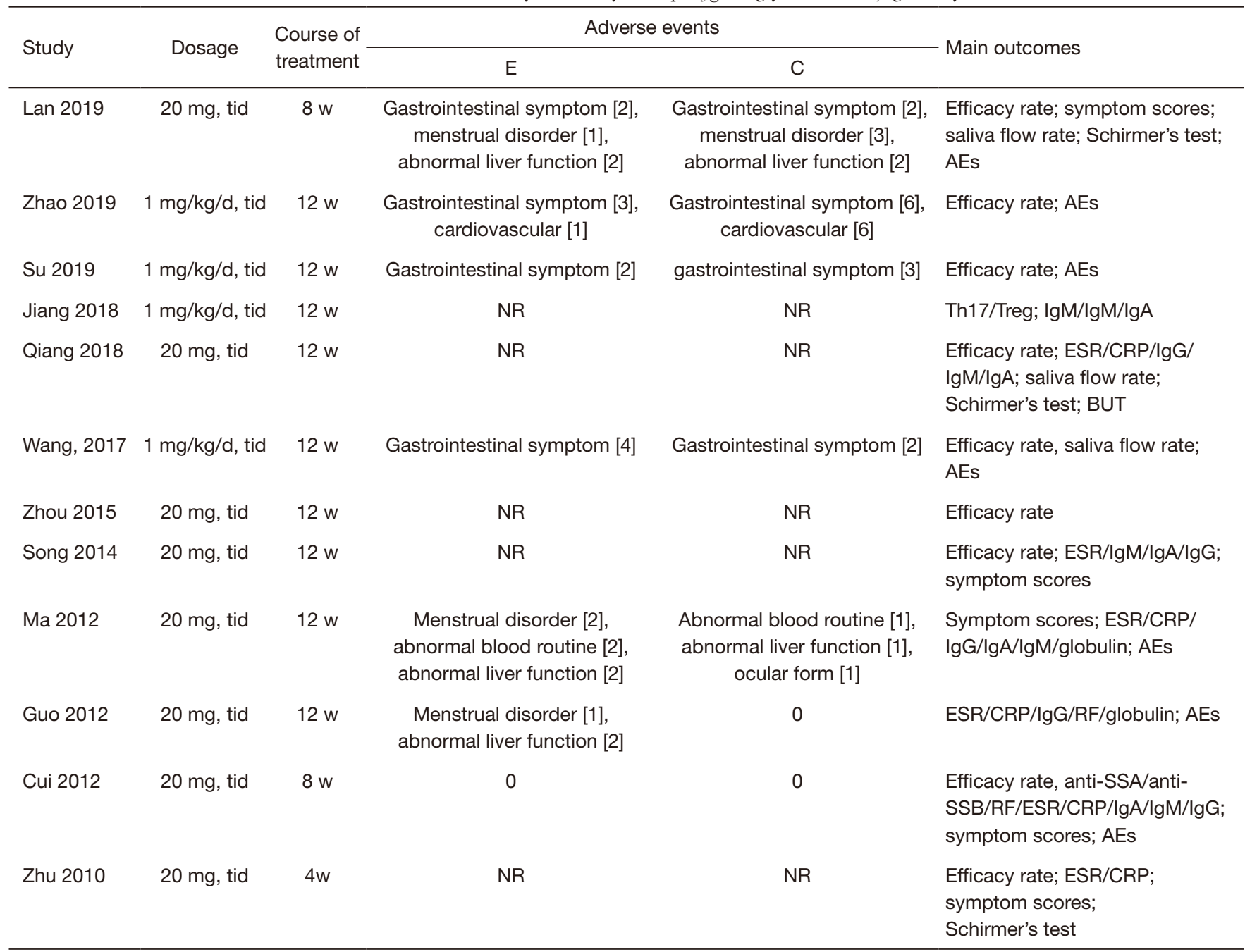

E, experimental group; C, control group; NR, no report; RCT, randomized controlled trial; M, male; F, female; w, weeks; d, days; tid, three times a day; AEs, adverse events; Th17, T helper 17; Treg, regulatory T; IgM/G/A, immunoglobulin M/G/A; ESR, erythrocyte sedimentation rate; CRP, C-reactive protein; BUT, break-up time; RF, rheumatoid factor; anti-SSA/B antibody, anti-Sjögren's syndrome A/B antibody.

blindness of participants and personnel (implementation bias), blindness of outcome assessment (monitoring bias), no complete result data (wear bias), selective reporting (reporting bias), and other biases. We used the method of low risk of bias, unclear risk of bias, or high risk of bias. In case of a disagreement between the two authors, we negotiated with a third reviewer. A funnel plot was used to analyze the publication bias across studies.

\section{Statistical analysis}

We used RevMan (version 5.3) to calculate the risk ratio (RR) in counting data or mean difference (MD) in quantitative data with a $95 \%$ confidence interval (CI). The standard mean difference (SMD) was used when the measurement standard differed among studies. Clinical heterogeneity was evaluated using the $\mathrm{I}^{2}$ method. Summary statistics were produced at first, and when $\mathrm{I}^{2}$ was $>50 \%$, subgroup analysis was used for clinical heterogeneity. If the value of the heterogeneity $\mathrm{I}^{2}$ (tested by the $\mathrm{I}^{2}$ statistic) was $<50 \%$, the fixed-effect model was selected; otherwise, the random effects model was used. A sensitivity analysis was performed if necessary. The inconsistent data extracted from the included studies are displayed in the Results section. 


\section{Outcome measures}

The primary outcome comprised symptom scores, including the EULAR Sjögren's syndrome disease activity index (ESSDAI), dry eyes, dry mouth, dry skin, and joint pain. The therapeutic evaluation was based on the standard formulated by the EULAR, which developed the ESSDAI scores in 2010 that are now widely used both clinically and in research (24).

The secondary outcomes were as follows: efficacy rate; serum index of immunoglobulin G (IgG), immunoglobulin $M(\operatorname{Ig} M)$, immunoglobulin A ( $\operatorname{IgA})$, erythrocyte sedimentation rate (ESR), C-reactive protein (CRP), rheumatoid factor (RF), anti-SS A/B antibody (anti-SSA/ B antibody), T helper 17 (Th17) cells, regulatory T (Treg) cells; physical index of saliva flow rate; Schirmer's test and break-up time (BUT); and adverse events.

\section{Results}

\section{Characteristics of included studies}

A total of 125 studies were retrieved from 7 databases, and 61 duplicate reports were eliminated. Overall, 34 records were excluded after the title and summary scanning, leaving 30 records. Finally, 12 articles (25-36) met the inclusion criteria based on PICOS, which were included in the current systematic review (Figure 1), including three $(32,33,35)$ unofficially published dissertations.

\section{Summary}

A total of 668 patients were included in the 12 studies. The characteristics of the included trials are listed in Tables 1,2. All trials met the diagnostic criteria, and 10 trials mentioned the diagnostic criteria used, of which two $(27,30)$ were confirmed by the hospital.

\section{Interventions}

This review involved 17 interventions, and we established subgroups based on different interventions. Two RCTs $(33,34)$ compared TGs alone with HCQ, whereas four trials $(29,32,35,36)$ compared TGs alone with HM. Five trials compared TGs in combination with total glucosides of paeony (TGP) and TGs alone $(26,27,30)$, and two trials compared TG + HM and TGs alone (25,31). The duration of treatment ranged from 4 to 12 weeks with a dosage of $60 \mathrm{mg} / \mathrm{d}$ or $1 \mathrm{mg} / \mathrm{kg} / \mathrm{d}$.

\section{Outcome indicators}

Five trials measured symptom scores $(25,32,33,35,36)$. Nine trials $(25-27,29-32,35,36)$ used efficacy rate as an outcome, seven trials measured serum index (28,29,32-36), and four trials reported physical index $(25,29,30,36)$. Seven trials reported adverse events $(25,26,27,30,33-35)$.

\section{Risk of bias assessment}

Although all 12 trials were randomized trials, only three trials $(26,27,30)$ documented the generation of random sequences (Figure 2). The risk of bias in one study (30) was considered as "high risk" because the integrated balance method was used for grouping. One study (33) reported the implementation and monitoring of blindness, while it considered the risk of breaking blindness as "high risk." According to data loss, four experiments $(28,32,34,35)$ had little data loss but did not report the reason, which was considered as "unclear risk." The protocols of three studies $(32,33,35)$ were accessible, and the established primary and secondary outcomes were reported according to the established plan. Therefore, we performed a low-risk evaluation. None of the studies described other biases. The risk of publication bias across studies has been presented in a funnel plot (Figure S1), implying a low-quality methodology and indicating that a publication bias may exist. The small sample size may be the main reason for this bias.

\section{Primary outcome: symptom scores}

One trial reported symptom scores of TGs in combination with TGP compared with TGs alone, and the combined therapies significantly reduced the scores of dry eyes (SMD $=-0.61,95 \%$ CI: -1.12 to $-0.10, \mathrm{P}=0.02)$ and dry mouth (SMD $=-1.29,95 \%$ CI: -1.84 to $-0.74, \mathrm{P}<0.00001)$. However, we found that TGs were as effective as the HM in terms of ESSDAI (SMD $=0.12,95 \%$ CI: -0.97 to $1.21, \mathrm{I}^{2}=85 \%$, $\mathrm{P}=0.83$ ) (Table 3) and relieving the symptoms of dry eyes ( $\mathrm{SMD}=0.00,95 \% \mathrm{CI}:-0.31$ to $\left.0.31, \mathrm{I}^{2}=0 \%, \mathrm{P}=0.99\right)$, joint pain (SMD $=0.01,95 \%$ CI: -0.92 to $0.95, \mathrm{I}^{2}=88 \%, \mathrm{P}=0.98$ ), and dry skin (SMD $=0.20,95 \%$ CI: -0.58 to $0.98, \mathrm{I}^{2}=83 \%$, $\mathrm{P}=0.62$ ), whereas the HM group seemed to have a better effect on relieving the symptom of dry mouth (SMD $=0.73,95 \%$ CI: 0.13 to $1.33, \mathrm{I}^{2}=69 \%, \mathrm{P}=0.02$ ). The clinical heterogeneity could not be solved by subgroup analysis, which may be related to the inconsistency of Chinese HM compound preparations.

\section{Secondary outcomes}

\section{Efficacy rate}

Subgroup analysis demonstrated that the efficacy of TGs 


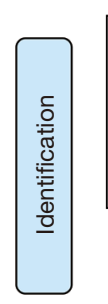

Records identified through database searching PubMed $(n=0)$, Cochrane $(n=0)$, Embase $(n=0)$, CNKI $(n=38)$, Wanfang $(n=19)$, $\operatorname{CQVIP}(n=27), \operatorname{CBM}(n=41)$ $(n=125)$

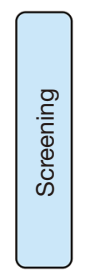

Records after duplicates removed

Additional records identified

through other sources

$(n=0)$
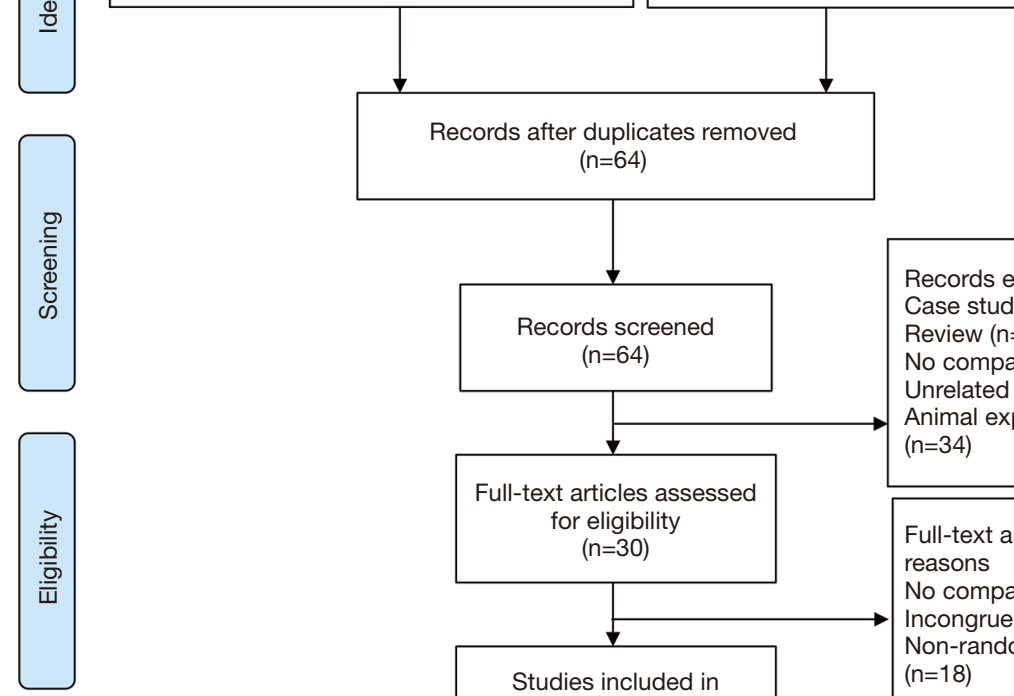
$(n=64)$
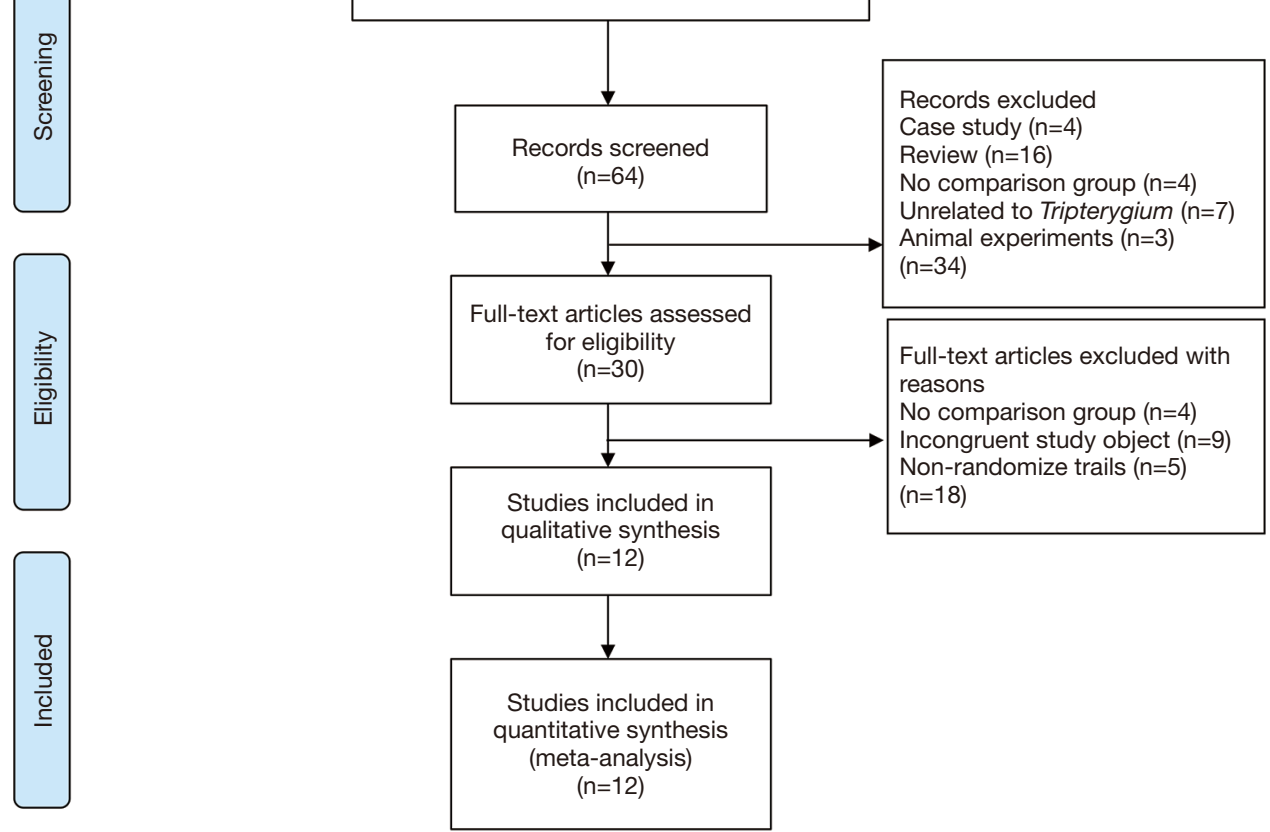

Figure 1 Flowchart of search strategy and study selection, according to the Preferred Reporting Items for Systematic Reviews and Meta-analyses (PRISMA) guidelines. EMBASE, Excerpta Medica database; CNKI, Chinese National Knowledge Infrastructure database; Wanfang, Wanfang Data Knowledge Service Platform; VIP, China Science and Technology Journal Database; CBM, Chinese Biomedicine Database.

vs. HM group did not have a significant difference (RR $=0.90,95 \%$ CI: 0.79 to $1.01, \mathrm{I}^{2}=0 \%, \mathrm{P}=0.07$; Table 4 ), and the TGs $v s$. HCQ group lacked sufficient data. The efficacy rate of combined medication with TGs was significantly higher that TGs alone (TG + TGP vs. TGs: $\mathrm{RR}=1.23$, $95 \%$ CI: 1.11 to $1.36, \mathrm{I}^{2}=0 \%, \mathrm{P}<0.00001$; $\mathrm{TG}+\mathrm{HM}$ vs. TGs: $\mathrm{RR}=1.27,95 \% \mathrm{CI}$ : 1.05 to $1.54, \mathrm{I}^{2}=0 \%, \mathrm{P}=0.01$ ). The clinical heterogeneity was solved by subgroup analysis, which indicated that the sources were interventions among subgroups.

\section{Serum index}

Subgroup analysis (Table 5) revealed that there was a significant difference between the HCQ and TG groups in reducing levels of CRP ( $\mathrm{MD}=-0.41,95 \% \mathrm{CI}:-0.71$ to $\left.-0.11, \mathrm{I}^{2}=0 \%, \mathrm{P}=0.007\right)$, globulin ( $\mathrm{MD}=-6.54,95 \% \mathrm{CI}$ : -9.20 to $\left.-3.88, \mathrm{I}^{2}=0 \%, \mathrm{P}<0.00001\right)$, and $\operatorname{IgA}(\mathrm{MD}=-0.64$, $95 \%$ CI: -1.10 to $-0.18, \mathrm{P}=0.06)$; however, other indices were not significant (ESR: $M D=-6.67,95 \% \mathrm{CI}:-13.27$ to $-0.08, \mathrm{I}^{2}=72 \%, \mathrm{P}=0.05$; IgG: $\mathrm{MD}=-3.11,95 \% \mathrm{CI}:-8.00$ to $1.78, \mathrm{I}^{2}=88 \%, \mathrm{P}=0.21$; IgM: $\mathrm{MD}=0.05,95 \% \mathrm{CI}:-0.16$ 
A

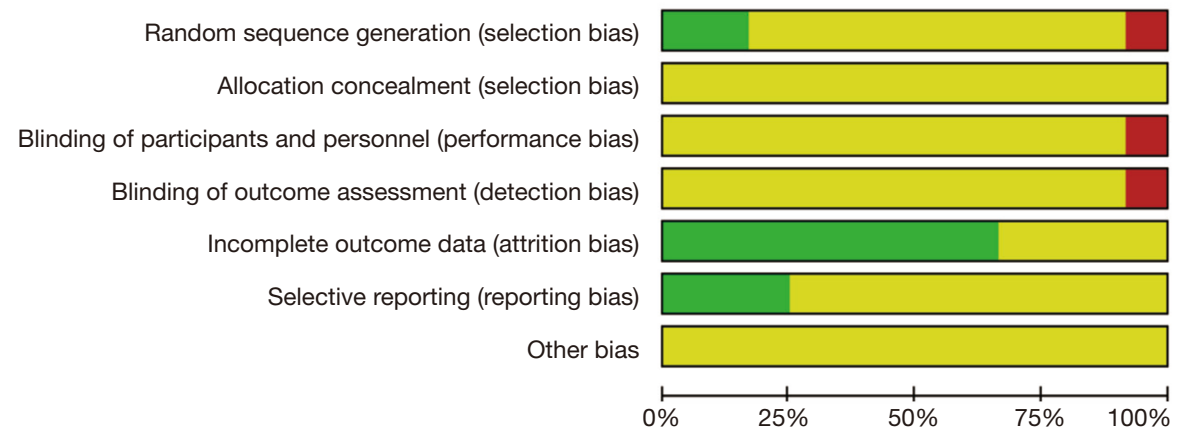

Low risk of bias

Unclear risk of bias

High risk of bias

B

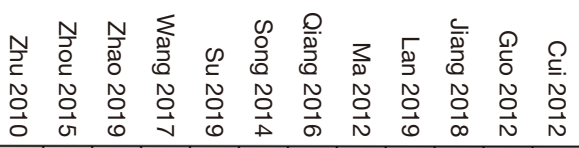

\begin{tabular}{|c|c|c|c|c|c|c|c|c|c|c|c|c|}
\hline$\sim$ & $\sim$ & + & (1) & + & $\sim$ & $\sim$ & $\sim$ & $\sim$ & $\sim$ & $\sim$ & $\sim$ & Random sequence generation (selection bias) \\
\hline$\sim$ & $\sim$ & $\sim$ & $\sim$ & $\sim$ & $\sim$ & $v$ & $\sim$ & $\sim$ & $\sim$ & $\nu$ & $\sim$ & Allocation concealment (selection bias) \\
\hline$\sim$ & $\sim$ & $\sim$ & $\sim$ & $\sim$ & $\sim$ & $\sim$ & (1) & $\sim$ & $\sim$ & $\sim$ & $\sim$ & Blinding of participants and personnel (performance bias) \\
\hline$\sim$ & $\sim$ & $\sim$ & $\sim$ & $\sim$ & $\sim$ & $\sim$ & (1) & $\sim$ & $\sim$ & $\sim$ & $\sim$ & Blinding of outcome assessment (detection bias) \\
\hline$\oplus$ & $\oplus$ & $\oplus$ & $\oplus$ & + & $\sim$ & + & + & + & $\sim$ & $\sim$ & $\sim$ & Incomplete outcome data (attrition bias) \\
\hline$\sim$ & $\sim$ & $\sim$ & $\sim$ & $\sim$ & $\oplus$ & $\sim$ & + & $\sim$ & $\sim$ & $\sim$ & + & Selective reporting (reporting bias) \\
\hline$v$ & $\sim$ & $v$ & $\nu$ & $v$ & $v$ & $v$ & $v$ & $v$ & $\nu$ & $v$ & $v$ & Other bias \\
\hline
\end{tabular}

Figure 2 Risk of bias in the included studies on the safety and efficacy of Tripterygium glycosides for Sjögren's syndrome. (A) Risk of bias graph; (B) risk of bias summary.

to $-0.26, \mathrm{P}=0.65$; RF: $\mathrm{MD}=-6.60,95 \% \mathrm{CI}:-16.31$ to 3.11 , $\mathrm{P}=0.18)$.

The CRP level of TG group was significantly higher than that of HM group ( $M D=2.48,95 \%$ CI: 0.21 to 4.75 , $\left.\mathrm{I}^{2}=24 \%, \mathrm{P}=0.03\right)$. TGs had similar results with $\mathrm{HM}$ in terms of ESR ( $M D=2.28,95 \%$ CI: -0.95 to $5.51, \mathrm{I}^{2}=10 \%$, $\mathrm{P}=0.17)$, IgG ( $\mathrm{MD}=1.06,95 \% \mathrm{CI}:-1.43$ to $3.56, \mathrm{I}^{2}=72 \%$, $\mathrm{P}=0.40)$, IgM ( $\mathrm{MD}=0.10,95 \% \mathrm{CI}:-0.16$ to $-0.09, \mathrm{I}^{2}=72 \%$, $\mathrm{P}=0.45)$, IgA ( $\mathrm{MD}=0.15,95 \% \mathrm{CI}:-0.14$ to $-0.44, \mathrm{I}^{2}=51 \%$, $\mathrm{P}=0.31), \mathrm{RF}(\mathrm{RR}=3.78,95 \% \mathrm{CI}: 0.47$ to $30.5, \mathrm{P}=0.21)$, antiSSA antibody ( $R R=1.35,95 \% \mathrm{CI}: 0.67$ to $2.72, \mathrm{P}=0.40$ ), and anti-SSB antibody (RR $=1.51,95 \%$ CI: 0.61 to 3.71 , $\mathrm{P}=0.37)$.

The comparison between TG + TGP and TGs indicated strong synergistic effects of the combination on production of IgG (MD $=-0.51,95 \%$ CI: -0.67 to $-0.35, \mathrm{P}<0.00001)$, $\operatorname{IgM}(\mathrm{MD}=-0.63,95 \% \mathrm{CI}:-1.17$ to $-0.09, \mathrm{P}=0.02), \operatorname{IgA}$ (TG + TGP $v s$. TGs: $M D=-3.43,95 \%$ CI: -4.71 to -2.15 , $\mathrm{P}<0.00001)$, Th17 cells (MD $=-0.21,95 \% \mathrm{CI}:-0.36$ to $0.06, \mathrm{P}=0.006)$, and Treg cells (MD $=0.59,95 \% \mathrm{CI}: 0.09$ to $1.09, \mathrm{P}=0.02)$. Clinical heterogeneity may correspond to differences in the method of administration and duration of follow-up.

\section{Physical index}

Compared with HM, TGs alone exhibited a significant difference in saliva flow rate (SMD $=-1.40,95 \%$ CI: -1.91 to $0.90, \mathrm{P}<0.00001$; Table 5) and BUT (SMD $=-0.59,95 \%$ CI: -1.05 to $-0.13, \mathrm{P}=0.01)$, whereas Schirmer's test results were not significant (SMD $=-0.14,95 \%$ CI: $-0.71,0.44$, $\left.\mathrm{I}^{2}=76 \%, \mathrm{P}=0.64\right)$.

The results showed that TGs in combination with TGP or $\mathrm{HM}$ increased the saliva flow rate $\mathrm{SMD}=1.73,95 \% \mathrm{CI}$ : 1.36 to $2.10, \mathrm{I}^{2}=0 \%, \mathrm{P}<0.00001$ ), and TGs in combination with TGP performed better in Schirmer's test of two eyes ( $\mathrm{SMD}=1.34,95 \% \mathrm{CI}: 0.95$ to $\left.1.73, \mathrm{I}^{2}=0 \%, \mathrm{P}<0.00001\right)$ than the groups treated with TGs alone. The clinical heterogeneity of Schirmer's test could not be solved by subgroup analysis, which may be related to differences in the specific operation methods. 
Table 3 Symptom scores of Tripterygium glycosides in Sjögren's syndrome treatment

\begin{tabular}{|c|c|c|c|}
\hline Trials & Comparisons & Effect estimates, SMD (95\% Cl) & $P$ value \\
\hline \multicolumn{4}{|c|}{ 1. Tripterygium glycosides versus hydroxychloroquine } \\
\hline \multicolumn{4}{|l|}{ 1.1 Dry mouse } \\
\hline Ma 2012 & Tripterygium glycosides versus hydroxychloroquine & $-0.12(-0.71,0.47)$ & 0.69 \\
\hline \multicolumn{4}{|c|}{ 2. Tripterygium glycosides versus herbal medicine } \\
\hline \multicolumn{4}{|l|}{ 2.1 ESSDAI } \\
\hline Cui 2012 & Tripterygium glycosides versus herbal medicine & $-0.46(-1.13,0.21)$ & \\
\hline Song 2014 & Tripterygium glycosides versus herbal medicine & $0.65(0.13,1.17)$ & \\
\hline Meta-analysis & & $0.12(-0.97,1.21)$ & 0.83 \\
\hline \multicolumn{4}{|l|}{ 2.2 Dry eyes } \\
\hline Zhu 2010 & Tripterygium glycosides versus herbal medicine & $0.14(-0.35,0.64)$ & \\
\hline Cui 2012 & Tripterygium glycosides versus herbal medicine & $0.14(-0.53,0.80)$ & \\
\hline Song 2014 & Tripterygium glycosides versus herbal medicine & $-0.23(-0.74,0.27)$ & \\
\hline Meta-analysis & & $-0.00(-0.31,0.31)$ & 0.99 \\
\hline \multicolumn{4}{|l|}{ 2.3 Dry mouse } \\
\hline Zhu 2010 & Tripterygium glycosides versus herbal medicine & $1.27(0.73,1.82)$ & \\
\hline Cui 2012 & Tripterygium glycosides versus herbal medicine & $0.62(-0.06,1.30)$ & \\
\hline Song 2014 & Tripterygium glycosides versus herbal medicine & $0.31(-0.20,0.82)$ & \\
\hline Meta-analysis & & $0.73(0.13,1.33)$ & 0.02 \\
\hline \multicolumn{4}{|l|}{ 2.4 Dry skin } \\
\hline Zhu 2010 & Tripterygium glycosides versus herbal medicine & $-0.41(-0.91,0.08)$ & \\
\hline Cui 2012 & Tripterygium glycosides versus herbal medicine & $0.16(-0.51,0.82)$ & \\
\hline Song 2014 & Tripterygium glycosides versus herbal medicine & $0.85(0.32,1.38)$ & \\
\hline Meta-analysis & & $0.20(-0.58,0.98)$ & 0.62 \\
\hline \multicolumn{4}{|l|}{2.5 Joint pain } \\
\hline Zhu 2010 & Tripterygium glycosides versus herbal medicine & $-0.18(-0.68,0.31)$ & \\
\hline Cui 2012 & Tripterygium glycosides versus herbal medicine & $1.06(0.35,1.78)$ & \\
\hline Song 2014 & Tripterygium glycosides versus herbal medicine & $-0.75(-1.27,-0.22)$ & \\
\hline
\end{tabular}

3. Tripterygium glycosides combined with total glucosides of paeony versus Tripterygium glycosides

$$
\begin{array}{r}
\text { 3.2 Dry eyes } \\
\text { Jiang } 2018
\end{array}
$$

3.3 Dry mouse

Jiang 2018
Tripterygium glycosides combined with total glucosides of paeony versus Tripterygium glycosides

Tripterygium glycosides combined with total glucosides of paeony versus Tripterygium glycosides
$-1.29(-1.84,0.74) \quad<0.00001$

SMDs, standard mean differences; $\mathrm{Cl}$, confidence interval. 
Table 4 Symptom scores of Tripterygium glycosides in Sjögren's syndrome treatment

\begin{tabular}{|c|c|c|c|}
\hline Trials & Comparisons & Effect estimates, RR (95\% Cl) & $P$ value \\
\hline Zhu 2010 & Tripterygium glycosides versus herbal medicine & $0.93(0.77,1.12)$ & \\
\hline Cui 2012 & Tripterygium glycosides versus herbal medicine & $0.94(0.72,1.24)$ & \\
\hline Song 2014 & Tripterygium glycosides versus herbal medicine & $0.78(0.58,1.04)$ & \\
\hline Meta-analysis & & $0.90(0.79,1.01)$ & 0.07 \\
\hline \multicolumn{4}{|c|}{ 2. Tripterygium glycosides combined with total glucosides of paeony versus Tripterygium glycosides } \\
\hline Wang 2017 & $\begin{array}{l}\text { Tripterygium glycosides combined with total glucosides of paeony } \\
\text { versus Tripterygium glycosides }\end{array}$ & $1.18(1.02,1.36)$ & \\
\hline Meta-analysis & & $1.23(1.11,1.36)$ & 0.0001 \\
\hline \multicolumn{4}{|c|}{ 3. Tripterygium glycosides combined with herbal medicine versus Tripterygium glycosides } \\
\hline Zhou 2015 & $\begin{array}{l}\text { Tripterygium glycosides combined with herbal medicine versus } \\
\text { Tripterygium glycosides }\end{array}$ & $1.39(1.00,1.94)$ & \\
\hline Lan 2019 & $\begin{array}{l}\text { Tripterygium glycosides combined with herbal medicine versus } \\
\text { Tripterygium glycosides }\end{array}$ & $1.22(0.96,1.54)$ & \\
\hline Meta-analysis & & $1.27(1.05,1.54)$ & 0.01 \\
\hline
\end{tabular}

$\mathrm{RR}$, risk ratio; $\mathrm{Cl}$, confidence interval.

\section{Adverse events}

By comparing TGs and HCQ, we found that their adverse events were not significantly different (abnormal liver function: $\mathrm{RR}=3.00,95 \% \mathrm{CI}$ : 0.50 to $18.06, \mathrm{I}^{2}=0 \%, \mathrm{P}=0.23$; abnormal blood routine: $\mathrm{RR}=2.00,95 \%$ CI: 0.20 to 20.49 , $\mathrm{P}=0.56$; ocular form: $\mathrm{RR}=0.33,95 \% \mathrm{CI}: 0.01$ to 7.76 , $\mathrm{P}=0.49$; menstrual disorder: $\mathrm{RR}=4.00,95 \% \mathrm{CI}: 0.47$ to 34.22, $\mathrm{I}^{2}=0 \%, \mathrm{P}=0.21$ ).

Table 5 shows that there was no significant difference in adverse effects between the TG + TGP and TG groups (gastrointestinal symptom: $\mathrm{RR}=0.82,95 \%$ CI: 0.35 to 1.91 , $\mathrm{I}^{2}=0 \%, \mathrm{P}=0.64$; cardiovascular: $\mathrm{RR}=0.17,95 \%$ CI: 0.02 to $1.33, \mathrm{P}=0.09$ ). In addition, the adverse events of TGs in combination with HM were similar to those of TGs alone (gastrointestinal symptom: $\mathrm{RR}=2.00,95 \% \mathrm{CI}: 0.19$ to 20.93, $\mathrm{P}=0.56$; menstrual disorder: $\mathrm{RR}=0.33,95 \%$ CI: 0.04 to $3.03, \mathrm{P}=0.33$; abnormal liver function: $\mathrm{RR}=1.00,95 \% \mathrm{CI}$ : 0.15 to $6.66, \mathrm{P}=1.00)$. The clinical heterogeneity in adverse events was solved by subgroup analysis, which indicated that its sources are interventions among subgroups.

\section{Discussion}

This systematic review included 12 RCTs to evaluate the effectiveness and safety of TGs in the treatment of SS. According to the EULAR guidelines (9), relieving SS symptoms should be the priority of first-line therapies. In accordance with HM, we demonstrated, to a limited extent, that combination therapy including TGs was effective at reducing dry eye or mouth as determined by the results of symptom score. Furthermore, TGs in combination with other treatments resulted in a synergistic benefit for the secretion function of the lacrimal gland (Schirmer's test) or salivary gland (saliva flow rate). As such, it appears that the underlying immunological mechanism of TGs is unclear, although previous reports have postulated that it is similar to steroids (37). Nonetheless, combinatorial treatments for SS that include TGs are beneficial for symptom relief. 
Table 5 Serum and physical indices of Tripterygium glycosides and associated adverse events in Sjögren's syndrome treatment

\begin{tabular}{|c|c|c|c|}
\hline Trials & Comparisons & $\begin{array}{l}\text { Effect estimates, MD/RR/SMD } \\
\qquad(95 \% \mathrm{Cl})\end{array}$ & $P$ value \\
\hline
\end{tabular}

1. Tripterygium glycosides versus hydroxychloroquine

1.1 Serum index

1.1.1 C-reactive protein

Ma $2012 \quad$ Tripterygium glycosides versus hydroxychloroquine

Guo 2012 Tripterygium glycosides versus hydroxychloroquine

Meta-analysis

1.1.2 Erythrocyte sedimentation rate

Ma $2012 \quad$ Tripterygium glycosides versus hydroxychloroquine

Guo 2012

Meta-analysis

1.1.3 Globulin

Ma 2012

Guo 2012

Meta-analysis

Tripterygium glycosides versus hydroxychloroquine

1.1.4 Immunoglobulin G

Ma 2012

Guo 2012

Meta-analysis

1.1.5 Immunoglobulin M

Ma 2012

Tripterygium glycosides versus hydroxychloroquine

1.1.6 Immunoglobulin A

Ma 2012

Tripterygium glycosides versus hydroxychloroquine

1.1.7 Rheumatoid factor

Guo 2012

Tripterygium glycosides versus hydroxychloroquine

1.2 Adverse events

1.2.1 Abnormal liver function

Ma 2012

Guo 2012

Tripterygium glycosides versus hydroxychloroquine

Tripterygium glycosides versus hydroxychloroquine

Meta-analysis

1.2.2 Abnormal blood routine

Ma 2012

Tripterygium glycosides versus hydroxychloroquine

1.2.3 Ocular form

Ma 2012

Tripterygium glycosides versus hydroxychloroquine

$$
\begin{aligned}
& \text { MD: }-0.41(-0.71,-0.11) \\
& \text { MD: }-1.90(-7.90,4.10) \\
& \text { MD: }-0.41(-0.72,-0.11)
\end{aligned}
$$

0.007

$$
\begin{gathered}
\text { MD: }-3.05(-8.59,2.49) \\
\text { MD: }-9.80(-14.02,-5.58) \\
\text { MD: }-6.67(-13.27,-0.08)
\end{gathered}
$$

0.05

MD: $-7.30(-10.80,-3.80)$

MD: $-5.50(-9.60,-1.40)$

MD: -6.54 (-9.20, -3.88)

$<0.00001$

MD: $-0.61(-3.00,1.78)$

MD: -5.60 (-7.95, -3.25)

MD: $-3.11(-8.00,1.78)$

0.21

MD: $0.05(-0.16,0.26)$

0.65

MD: $-0.64(-1.10,-0.18)$

0.006

MD: $6.60(-16.31,3.11)$

0.18

RR: 2.00 (0.20, 20.49)

RR: $5.00(0.26,96.13)$

RR: $3.00(0.50,18.06)$

RR: $2.00(0.20,20.49)$

0.56

RR: $0.33(0.01,7.76)$

0.49

Table 5 (continued) 
Table 5 (continued)

\begin{tabular}{lcc}
\hline Trials & Comparisons & Effect estimates, MD/RR/SMD \\
$(95 \% \mathrm{Cl})$ & $\mathrm{P}$ value
\end{tabular}

1.2.4 Menstrual disorder

Ma 2012 Tripterygium glycosides versus hydroxychloroquine

RR: $5.00(0.25,98.52)$

Guo 2012

Tripterygium glycosides versus hydroxychloroquine

RR: $3.00(0.13,68.26)$

Meta-analysis

RR: $4.00(0.47,34.22)$

0.21

2. Tripterygium glycosides versus herbal medicine

2.1 Serum index

2.1.1 C-reactive protein

Zhu 2010

Tripterygium glycosides versus herbal medicine

MD: $2.73(-2.32,7.78)$

Cui 2012

Tripterygium glycosides versus herbal medicine

Qiang 2018

Tripterygium glycosides versus herbal medicine

MD: $-3.22(-10.48,4.04)$

MD: $3.20(0.49,5.91)$

Meta-analysis

MD: $2.48(0.21,4.75)$

0.03

2.1.2 Erythrocyte sedimentation rate

Zhu 2010

Tripterygium glycosides versus herbal medicine

Cui 2012

Song 2014

Qiang 2018

Meta-analysis

2.1.3 Immunoglobulin G

Cui 2012

Song 2014

Qiang 2018

Meta-analysis

Tripterygium glycosides versus herbal medicine Tripterygium glycosides versus herbal medicine Tripterygium glycosides versus herbal medicine

Tripterygium glycosides versus herbal medicine

Tripterygium glycosides versus herbal medicine

Tripterygium glycosides versus herbal medicine

2.1.4 Immunoglobulin M

Cui 2012

Qiang 2018

Song 2014

Meta-analysis

2.1.5 Immunoglobulin A

Cui 2012

Song 2014

Qiang 2018

Meta-analysis

Tripterygium glycosides versus herbal medicine Tripterygium glycosides versus herbal medicine Tripterygium glycosides versus herbal medicine

Tripterygium glycosides versus herbal medicine

Tripterygium glycosides versus herbal medicine

Tripterygium glycosides versus herbal medicine

2.1.6 Rheumatoid factor

Cui 2012

Tripterygium glycosides versus herbal medicine
MD: $1.07(-6.81,8.95)$

MD: $-4.27(-15.76,7.22)$

MD: $1.36(-2.85,5.57)$

MD: $6.08(0.53,11.63)$

MD: $2.28(-0.95,5.51)$

0.17

MD: $-1.70(-4.59,1.19)$

MD: $1.41(-1.01,3.83)$

MD: $2.83(1.14,4.52)$

MD: $1.06(-1.43,3.56)$

0.40

MD: $-0.04(-0.32,0.24)$

MD: $0.35(0.14,0.56)$

MD: $-0.03(-0.28,0.22)$

MD: $0.10(-0.16,0.37)$

0.45

MD: $0.04(-0.37,0.45)$

MD: $-0.04(-0.39,0.31)$

MD: $0.41(0.10,0.72)$

MD: $0.15(-0.14,0.44)$

0.31

RR: $3.78(0.47,30.5)$
0.21

Table 5 (continued) 
Table 5 (continued)

\begin{tabular}{|c|c|c|c|}
\hline Trials & Comparisons & $\begin{array}{l}\text { Effect estimates, MD/RR/SMD } \\
(95 \% \mathrm{Cl})\end{array}$ & $P$ value \\
\hline
\end{tabular}

2.1.7 Anti-Sjögren's syndrome A antibody

Cui $2012 \quad$ Tripterygium glycosides versus herbal medicine

RR: $1.35(0.67,2.72)$

0.40

2.1.8 Anti-Sjögren's syndrome B antibody

Cui 2012

Tripterygium glycosides versus herbal medicine

2.2 Physical index

2.2.1 Saliva flow rate

Qiang 2018 Tripterygium glycosides versus herbal medicine

2.2.2 Schirmer's test

Zhu 2010

Tripterygium glycosides versus herbal medicine

Zhu 2010

Qiang 2018

Meta-analysis

Tripterygium glycosides versus herbal medicine

Tripterygium glycosides versus herbal medicine

2.2.3 Break-up time

Qiang 2018

Tripterygium glycosides versus herbal medicine
RR: $1.51(0.61,3.71)$

SMD: $-1.40(-1.91,-0.90)$

$<0.00001$

SMD: $-0.26(-0.76,0.24)$

SMD: $0.43(-0.07,0.93)$

SMD: $-0.56(-1.02,-0.10)$

SMD: $-0.14(-0.71,0.44)$

0.64

SMD: $-0.59(-1.05,-0.13)$

3. Tripterygium glycosides combined with total glucosides of paeony versus Tripterygium glycosides

3.1 Serum index

3.1.1 Immunoglobulin G

Jiang 2018

3.1.2 Immunoglobulin M

Jiang 2018

3.1.3 Immunoglobulin A

Jiang 2018

3.1.4 T helper 17 cell

Jiang 2018

3.1.5. Regulatory $\mathrm{T}$ cell

Jiang 2018

3.2 physical index

3.2.1 Saliva flow rate

Wang 2017

Tripterygium glycosides combined with total glucosides of paeony versus Tripterygium glycosides
Tripterygium glycosides combined with total glucosides of paeony versus Tripterygium glycosides

Tripterygium glycosides combined with total glucosides of paeony versus Tripterygium glycosides

Tripterygium glycosides combined with total glucosides of paeony versus Tripterygium glycosides

Tripterygium glycosides combined with total glucosides of paeony versus Tripterygium glycosides

Tripterygium glycosides combined with total glucosides of paeony versus Tripterygium glycosides
MD: $-0.51(-0.67,-0.35)$

$<0.00001$

MD: $-0.63(-1.17,0.09)$

0.02

MD: $-3.43(-4.71,-2.15)$

$<0.00001$

MD: $-0.21(-0.36,0.06)$

0.006

MD: $0.59(0.09,1.09)$

0.02

Table 5 (continued) 
Table 5 (continued)

\begin{tabular}{|c|c|c|c|}
\hline Trials & Comparisons & $\begin{array}{l}\text { Effect estimates, MD/RR/SMD } \\
\qquad(95 \% \mathrm{Cl})\end{array}$ & $P$ value \\
\hline \multicolumn{4}{|l|}{ 3.3 Adverse events } \\
\hline Wang 2017 & $\begin{array}{l}\text { Tripterygium glycosides combined with total } \\
\text { glucosides of paeony versus Tripterygium glycosides }\end{array}$ & RR: $2.00(0.38,10.42)$ & \\
\hline Su 2019 & $\begin{array}{l}\text { Tripterygium glycosides combined with total } \\
\text { glucosides of paeony versus Tripterygium glycosides }\end{array}$ & RR: $0.67(0.12,3.71)$ & \\
\hline Meta-analysis & & RR: $0.82(0.35,1.91)$ & 0.64 \\
\hline \multicolumn{4}{|c|}{ 3.3.2 Cardiovascular } \\
\hline \multicolumn{4}{|c|}{ 4. Tripterygium glycosides combined with herbal medicine versus Tripterygium glycosides } \\
\hline \multicolumn{4}{|l|}{ 4.1 Physical index } \\
\hline \multicolumn{4}{|c|}{ 4.1.1 Saliva flow rate } \\
\hline Lan 2019 & $\begin{array}{l}\text { Tripterygium glycosides combined with herbal } \\
\text { medicine versus Tripterygium glycosides }\end{array}$ & SMD: $1.97(1.36,2.59)$ & $<0.00001$ \\
\hline \multicolumn{4}{|c|}{ 4.1.2 Schirmer's test } \\
\hline Lan 2019 & $\begin{array}{l}\text { Tripterygium glycosides combined with herbal } \\
\text { medicine versus Tripterygium glycosides }\end{array}$ & SMD: $1.37(0.81,1.93)$ & \\
\hline \multicolumn{4}{|c|}{ 4.2.1 Gastrointestinal symptom } \\
\hline Lan 2019 & $\begin{array}{l}\text { Tripterygium glycosides combined with herbal } \\
\text { medicine versus Tripterygium glycosides }\end{array}$ & RR: $2.00(0.19,20.93)$ & \\
\hline \multicolumn{4}{|c|}{ 4.2.2 Menstrual disorder } \\
\hline Lan 2019 & $\begin{array}{l}\text { Tripterygium glycosides combined with herbal } \\
\text { medicine versus Tripterygium glycosides }\end{array}$ & RR: $0.33(0.04,3.03)$ & 0.33 \\
\hline \multicolumn{4}{|c|}{ 4.2.3 Abnormal liver function } \\
\hline Lan 2019 & $\begin{array}{l}\text { Tripterygium glycosides combined with herbal } \\
\text { medicine versus Tripterygium glycosides }\end{array}$ & RR: $0.17(0.02,1.33)$ & 1.00 \\
\hline
\end{tabular}

SMDs, standard mean differences; RR, risk ratio; MD, mean difference; Cl, confidence interval.

TGs reportedly reduce systemic inflammation in SS patients by reducing CRP levels, which are independently associated with functional impairment in SS patients (38). The results of the present review provide evidence that TGs have a stronger therapeutic effect on reducing the level of CRP than HCQ or HM in patients with SS.

Therapeutics that reduce the proliferation of B cells, including TGs (39) and HCQ (40), have been used to 
treat SS. Indeed, SS is considered an autoimmune disease associated with hyperactivity, a pathologic autoantibody response of B cells (41), and elevated levels of serum IgG (42). Therefore, the levels of immunoglobulins in peripheral blood are considered to be important indicators of SS activity (7). Our results demonstrated that TGs reduced the level of globulin or IgA to an extent greater than HCQ. A previous experiment in animals (39) demonstrated that TGs and HCQ effectively reduced the expression of genes related to inflammation and autoimmunity. Therefore, combination therapy including TGs with other therapies may be more effective than single treatment interventions. The present meta-analysis demonstrated that TGs combined with TGP significantly reduced the levels of CRP and immunoglobulins (IgG, $\operatorname{Ig} M$, and $\operatorname{IgA})$ to an extent greater than TGs alone, which may be related to the synergistic effect of TGP on reducing immunoglobulins (43) or regulating immune homeostasis by modulating the Th17/Treg ratio (28).

Despite the promising therapeutic potential of TGs for patients with SS, the incidence of adverse events is worthy of discussion. This review demonstrated that the administration of TGs alone or in combination with other therapies resulted in gastrointestinal symptoms in four studies (23 cases), menstrual disorder in three studies (six cases), abnormal liver function in three studies (eight cases), cardiovascular events in one study (seven cases), abnormal blood function in one study (three cases), and ocular form in one study (one case) (see Figure S2). The results of the present review demonstrate that patients in the studies involving optimal dosage and duration of TG administration did not experience more adverse events compared to HCQ, which is in line with a previous study that reported that TGs resulted in fewer adverse events than HCQ in an animal model of SS (39). However, suboptimal treatment courses, combined interventions, and dosages of previous studies have resulted in an elevated incidence of TGs in previous trials, including the presence of intestinal toxicity, reproductive toxicity, hepatotoxicity, and hematotoxicity (17). As such, future studies should prevent TG-related toxicity by controlling drug dosage and clinical use time (44), as well as improving the mode of delivery (45) and compatibility in glycyrrhiza (46).

This study had several inherent limitations. First, the quality of the trials included in this review was low. For instance, only four trials reported random methods, one trial reported blinding methods, and no other biases were reported. Second, the baseline management of children with SS or secondary SS was not specifically reported. Third, the sample sizes of the included studies were often insufficient to provide adequate conclusions. Future studies are warranted incorporating a larger sample size with multicenter RCT methodologies, more comprehensively and objectively evaluating the efficacy and safety of TGs for the treatment of SS.

\section{Conclusions}

In conclusion, TGs can be considered potentially clinically effective agents for the treatment of SS. The administration of TGs alone reduced systemic inflammatory indices (CRP levels) and immunoglobulins (IgA and globulin levels) to an extent greater than HCQ. Furthermore, the combination of TGs with other therapies reduced dryness symptom scores and the levels of immunoglobulins (IgG, IgM, and IgA), in addition to enhancing the efficacy rate and secretion function of lacrimal (Schirmer's test) and salivary glands (saliva flow rate). However, the potential benefits and safety of TGs should be further investigated using high-quality, multi-center, and large-scale RCTs.

\section{Acknowledgments}

The authors thank Dr. Jennifer Noah's wonderful suggestions and edits.

Funding: This work was supported by grants from the National Key Research and Development Program of China (grant number 2018YFC1705305), NSFC of China (grant numbers 82074427, 81874470, 81671959, and 81973860), National Youth Foundation of China (grant numbers 81904214 and 82004235), Xinglin Youth Scholar of Shanghai University of Traditional Chinese Medicine (grant number RY411.33.10), Innovative Training Program for Graduate Students in Shanghai University of Traditional Chinese Medicine (grant number JY611.02.03.83), the Shanghai Key Clinical Specialty Construction Project (grant number shslczdzk05001), the Shanghai Three-year Action Plan for the Development of Traditional Chinese Medicine [grant numbers ZY(2018-2020)-FWTX-4010, ZY(20182020)-FWTX-1008], and the Shanghai Pujiang Talent Plan (grant number 2020PJD067).

\section{Footnote}

Reporting Checklist: The authors have completed the PRISMA reporting checklist. Available at https://dx.doi. 
org/10.21037/apm-21-256

Conflicts of Interest: All authors have completed the ICMJE uniform disclosure form (available at https://dx.doi. org/10.21037/apm-21-256). The authors have no conflicts of interest to declare.

Ethical Statement: The authors are accountable for all aspects of the work in ensuring that questions related to the accuracy or integrity of any part of the work are appropriately investigated and resolved.

Open Access Statement: This is an Open Access article distributed in accordance with the Creative Commons Attribution-NonCommercial-NoDerivs 4.0 International License (CC BY-NC-ND 4.0), which permits the noncommercial replication and distribution of the article with the strict proviso that no changes or edits are made and the original work is properly cited (including links to both the formal publication through the relevant DOI and the license). See: https://creativecommons.org/licenses/by-nc-nd/4.0/.

\section{References}

1. Zhang W, Li X, Xu D, et al. Recommendations of diagnosis and treatment of primary Sjögren's syndrome in China. Zhonghua Nei Ke Za Zhi 2020;59:269-276.

2. Chinese Medical Association. Rheumatology Section of Clinical Medical Guide. Tao F. editor. Beijing: People's Medical Publishing House, 2005:40-4.

3. Bowman SJ, Ibrahim GH, Holmes G, et al. Estimating the prevalence among Caucasian women of primary Sjögren's syndrome in two general practices in Birmingham, UK. Scand. J. Rheumatol 2004;33:39-43.

4. Ramos-Casals M, Brito-Zerón P, Solans R, et al. Systemic involvement in primary Sjogren's syndrome evaluated by the EULAR-SS disease activity index: analysis of 921 Spanish patients (GEAS-SS Registry). Rheumatology (Oxford) 2014;53:321-31.

5. Fisher BA, Brown RM, Bowman SJ, et al. A review of salivary gland histopathology in primary Sjo gren's syndrome with a focus on its potential as a clinical trials biomarker. Ann Rheum Dis 2015;74:1645-50.

6. Vivino FB, Al-Hashimi I, Khan Z, et al. Pilocarpine tablets for the treatment of dry mouth and dry eye symptoms in patients with Sjogren syndrome: a randomized, placebocontrolled, fixed-dose, multi-center trial. Arch Intern Med 1999;159:174-81.
7. Seror R, Ravaud P, Bowman SJ, et al. EULAR Sjogren's syndrome disease activity index: development of a consensus systemic disease activity index for primary Sjogren's syndrome. Ann Rheum Dis 2010;69:1103-9.

8. Callaghan R, Prabu A, Allan RB, et al. Direct healthcare costs and predictors of costs in patients with primary Sjogren's syndrome. Rheumatology (Oxford) 2007;46:105-11.

9. Ramos-Casals M, Brito-Zerón P, Bombardieri S, et al. EULAR recommendations for the management of Sjögren's syndrome with topical and systemic therapies. Ann Rheum Dis 2020;79:3-18.

10. Letaief H, Lukas C, Barnetche T, et al. Efficacy and safety of biological DMARDs modulating $B$ cells in primary Sjögren's syndrome: systematic review and meta-analysis. Joint Bone Spine 2018;85:15-22.

11. Law SK, Simmons MP, Techen N, et al. Molecular analyses of the Chinese herb Leigongteng (Tripterygium wilfordii Hook.f.). Phytochemistry 2011;72:21-6.

12. Yao JR, Sun Y, Luo SK, et al. Research progress of Tripterygium glycosides in clinical application. Chinese Journal of New Drugs and Clinical Remedies 2010;29:179-82.

13. Du X, Nyagblordzro M, An L, et al. Pharmacokinetic and Toxicological Characteristics of Tripterigium Glycosides and Their Derivatives. Curr Drug Metab 2018;19:605-27.

14. Wang XW, Tian RM, Yang YQ, et al. Tripterigium glycoside fraction $\mathrm{n} 2$ ameliorates adriamycin-induced nephrotic syndrome in rats by suppressing apoptosis. J Ethnopharmacol 2020;257:112789.

15. Luo Y, Kuai L, Chen J, et al. Efficacy and safety of Tripterygium wilfordii Hook. f. for oral lichen planus: Evidence from 18 randomized controlled trials. Phytother Res 2020;34:2180-91.

16. Zhou YY, Xia X, Peng WK, et al. The Effectiveness and Safety of Tripterygium wilfordii Hook. F Extracts in Rheumatoid Arthritis: A Systematic Review and MetaAnalysis. Front Pharmacol 2018;9:356.

17. Ru Y, Luo Y, Zhou Y, et al. Adverse Events Associated with Treatment of Tripterygium wilfordii Hook F: A Quantitative Evidence Synthesis. Front Pharmacol 2019;10:1250.

18. Liu L, Zhao H, Sun X, et al. Efficacy and safety of Tripterygium wilfordii hook $\mathrm{F}$ for chronic urticaria: a systematic review and meta-analysis. BMC Complement Altern Med 2018;18:243.

19. Jiang Q, Wang HL, Gong X, et al. Rheumatoid arthritis disease and syndrome diagnosis and treatment guidelines. 
Journal of Traditional Chinese Medicine 2018;59:1794-800.

20. RACGP Rheumatoid Arthritis Working Group. Clinical guideline for the diagnosis and management of early rheumatoid arthritis. National Health and Medical Research Council. Melbourne: The Royal Australian College of General Practitioners, 2009:1-46.

21. Chen XQ, Jin YY, Tang G. New Materia Medica. Beijing: People's Medical Publishing House, 2011:703.

22. Wang YD, Wang Q, Zhang JB, et al. Research progress on chemical constituents and quality control of Tripterygium wilfordii preparations. China Journal of Chinese Materia Medica 2019;44:3368-73.

23. Liberati A, Altman DG, Tetzlaff J, et al. The PRISMA statement for reporting systematic reviews and metaanalyses of studies that evaluate healthcare interventions: explanation and elaboration. BMJ 2009;339:b2700.

24. Seror R, Theander E, Brun JG, et al. Validation of EULAR primary Sjögren's syndrome disease activity (ESSDAI) and patient indexes (ESSPRI). Ann Rheum Dis 2015;74:859-66.

25. Lan JZ, Li WJ, Zhou M. Treatment of Primary Sjogren's Syndrome with Tripterygium Wilfordii Tablets and Zhibai Dihuang Decoction. Jiangxi Journal of Traditional Chinese Medicine 2019;50:42-4.

26. Zhao L. Effect of Tripterygium wilfordii polyglycosides combined with total paeony glycosides on Sjogren's syndrome. Medical Journal of People's Health 2019;31:127-8.

27. Su YH, Meng S, Liu YJ, et al. Clinical efficacy and safety of Tripterygium wilfordii polyglycoside combined with total paeony glycoside in the treatment of Sjogren's syndrome. China Health Vision 2019;19:79.

28. Jiang Y, Zhang N. Effects of Tripterygium wilfordii polyglycosides combined with total paeony glycosides on serum Th17/Treg balance and immune function in patients with Sjogren's syndrome. Guizhou Medical Journal 2018;42:1446-7.

29. Qiang JH, Xue XC. Clinical effect of Huoxue Jiedu prescription in the treatment of primary Sjogren syndrome. Clinical Research and Practice 2018;3:114-5.

30. Wang XH. Effect of Tripterygium wilfordii glycosides combined with total paeony glycosides on salivary flow rate in patients with Sjogren's syndrome. Shenzhen Journal of Integrated Traditional Chinese and Western Medicine 2017;27:34-5.

31. Zhou CH. Observation on 30 Cases of Primary Sjogren's Syndrome Treated by Integrated Traditional Chinese and Western Medicine. Journal of Practical Traditional
Chinese Medicine 2015;31:1015-6.

32. Song ZC. Zaobiqing clinical observation of the efficacy of the treatment of primary Sjögren's syndrome. Master's degree. Jinan: Shandong University of Traditional Chinese Medicine, 2014.

33. Ma CG. The clinical Research of Tripterygium Glycosides in Treating High Hypergammaglobulinemia of the patients with primary Sjögren's syndrome. Master's degree. Nanjing: Nanjing University of Chinese Medicine, 2012.

34. Guo YK, Ma CG, Ji W. Tripterygium Glycosides Treat Primary Sicca Syndrome with Hyperglobulinemia. Journal of Zhejiang Chinese Medical University 2012;36:770-2.

35. Cui MY. Clinical and Experimental Study of Huoxue Jiedu Yangyin Shengjin Recipe Interfering with Sjogren's Syndrome. Doctor's degree. Beijing: Beijing University of Chinese Medicine, 2012.

36. Zhu YL, Wei N, Hou XJ. Treatment of Sjogren syndrome with Huoxuejiedu Formula in 63 cases. Modern Chinese Clinical Medicine 2010;17:1-3.

37. Ke XY, Zhang HC. Observation of curative effect of oral Tripterygium wilfordii polyglycoside on Sjoegren syndrome. Chinese Journal of Practical Ophthalmology 2007;25:315-6.

38. Hackett KL, Newton JL, Frith J, et al. Impaired functional status in primary Sjögren's syndrome. Arthritis Care Res (Hoboken) 2012;64:1760-4.

39. Li CL, He J, Li ZG, et al. Effects of Multi-glycosides of Tripterygium wilfordiion in the Treatment of Sjögren's Syndrome in the Non-obese Diabetic Mouse Model. Chin J Dent Res 2015;18:95-101.

40. Bodewes ILA, Gottenberg JE, van Helden-Meeuwsen $\mathrm{CG}$, et al. Hydroxychloroquine treatment downregulates systemic interferon activation in primary Sjögren's syndrome in the JOQUER randomized trial. Rheumatology (Oxford) 2020;59:107-11.

41. Kim JW, Kim SM, Park JS, et al. Metformin improves salivary gland inflammation and hypofunction in murine Sjögren's syndrome. Arthritis Res Ther 2019;21:136.

42. Shen Y, Ma Y, Xie J, et al. A regulatory role for CD72 expression on B cells and increased soluble CD72 in primary Sjogren's syndrome. BMC Immunol 2020;21:21.

43. Feng Z, Zhang BQ, Zhu YM, et al. The Effectiveness and Safety of Total Glucosides of Paeony in Primary Sjögren's Syndrome: A Systematic Review and Meta-Analysis. Front Pharmacol 2019;10:550.

44. Song CY, Xu YG, Lu YQ. Use of Tripterygium wilfordii Hook $\mathrm{F}$ for immune-mediated inflammatory diseases: progress and future prospects. J Zhejiang Univ Sci B 
2020;21:280-90.

45. He YM, Yao YY, Chen YL, et al. Research progress of Tripterygium wilfordii preparations. China Pharmacy 2017;28:551-4.

Cite this article as: Luo Y, Zhang Y, Kuai L, Xing M, Ru Y, Luo Y, Liu L, Chen J, Li B, Li X. Efficacy and safety of Tripterygium glycosides in Sjögren's syndrome treatment: evidence from 12 randomized controlled trials. Ann Palliat Med 2021;10(7):8215-8231. doi: 10.21037/apm-21-256
46. Li YS, Tong PJ, Ma HZ. Toxicity attenuation and efficacy potentiation effect of liquorice on treatment of rheumatoid arthritis with Tripterygium wilfordii. Zhongguo Zhong Xi Yi Jie He Za Zhi 2006;26:1117-9. 


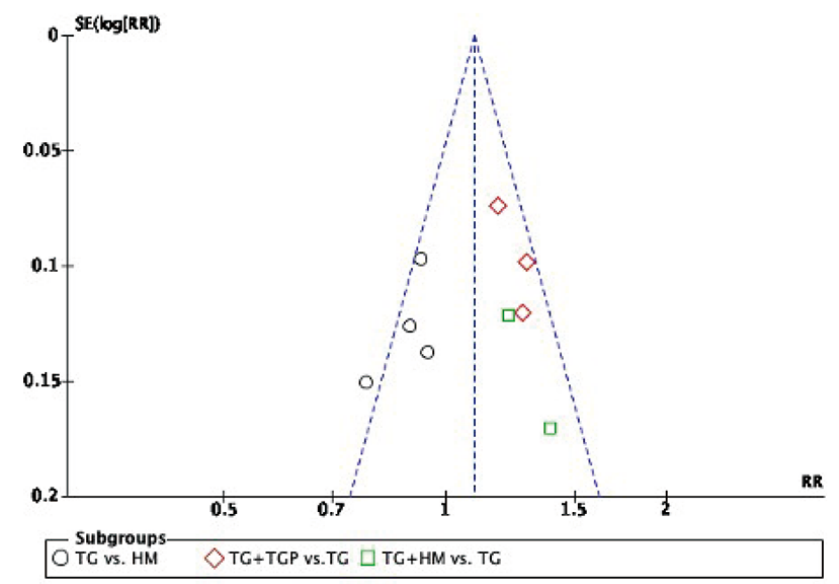

Figure S1 Funnel plot on the safety and efficacy of Tripterygium glycosides for Sjögren's syndrome. TG, Tripterygium glycosides; HM, herbal medicine; TGP, total glucosides of paeony.

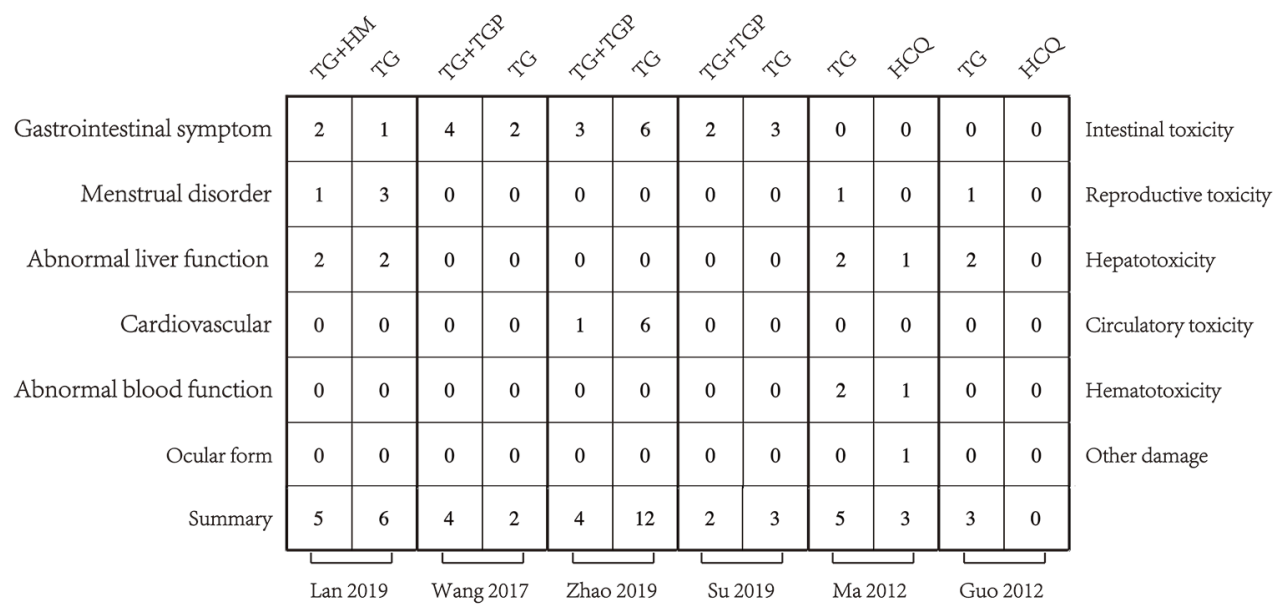

Figure S2 Mapping of specific adverse events between Tripterygium glycosides and control groups. TG, Tripterygium glycosides; HM, herbal medicine; TGP, total glucosides of paeony; HCQ, hydroxychloroquine. 
Table S1 Molecular structure of main chemical constituents of Tripterygium glycosides

\begin{tabular}{|c|c|c|}
\hline Name & Molecular formula & Structure \\
\hline Celastrol & $\mathrm{C}_{29} \mathrm{H}_{38} \mathrm{O}_{4}$ & \\
\hline Wilforlide A & $\mathrm{C}_{30} \mathrm{H}_{46} \mathrm{O}_{3}$ & \\
\hline Triptolide & $\mathrm{C}_{20} \mathrm{H}_{22} \mathrm{O}_{6}$ & \\
\hline Triptophenolide & $\mathrm{C}_{20} \mathrm{H}_{24} \mathrm{O}_{3}$ & \\
\hline Triptolide & $\mathrm{C}_{20} \mathrm{H}_{24} \mathrm{O}_{6}$ & \\
\hline Wilforine & $\mathrm{C}_{43} \mathrm{H}_{49} \mathrm{NO}_{18}$ & \\
\hline
\end{tabular}




\begin{tabular}{|c|c|}
\hline Database & Search strategy of electronic database in sequence \\
\hline \multirow[t]{11}{*}{ PubMed } & 1. Tripterygium [Mesh] \\
\hline & 2. Tripterygium glycoside [Title/Abstract] \\
\hline & 3. Radix tripterygium [Title/Abstract] \\
\hline & 4 TG [Title/Abstract $]$ \\
\hline & 5. 1 or 2 or 3 or 4 \\
\hline & 6. Sjögren's Syndrome [Mesh] \\
\hline & 7. Sjogren's Syndrome [Title/Abstract] \\
\hline & 8. Sicca [Title/Abstract] \\
\hline & 9. SS [Title/Abstract] \\
\hline & 10. 6 or 7 or 8 or 9 or 10 \\
\hline & 11. 5 and 10 \\
\hline \multirow[t]{11}{*}{ Embase } & 1. Tripterygium'/exp \\
\hline & 2. Tripterygium glycoside' \\
\hline & 3. Radix tripterygium' \\
\hline & 4. TG' \\
\hline & 5. 1 or 2 or 3 or 4 \\
\hline & 6. Sjögren's Syndrome'/exp \\
\hline & 7. Sjogren's Syndrome' \\
\hline & 8. Sicca' \\
\hline & 9. SS' \\
\hline & 10. 6 or 7 or 8 or 9 or 10 \\
\hline & 11. 5 and 10 \\
\hline \multirow[t]{11}{*}{ Cochrane Central Register of Controlled Trials } & 1. MeSH descriptor: [Tripterygium] explode all trees \\
\hline & 2. Tripterygium glycoside:ti,ab,kw \\
\hline & 3. Radix tripterygium:ti,ab,kw \\
\hline & 4. TG:ti,ab,kw \\
\hline & 5. 1 or 2 or 3 or 4 or 5 \\
\hline & 6. MeSH descriptor: [Sjögren's Syndrome] explode all trees \\
\hline & 7. Sjogren's Syndrom:ti,ab,kw \\
\hline & 8. Sicca:ti,ab,kw \\
\hline & 9. SS:ti,ab,kw \\
\hline & 10. 6 or 7 or 8 or 9 \\
\hline & 11. 5 and 10 \\
\hline \multirow[t]{6}{*}{ CNKI \& CQVIP \& Wanfang \& CBM } & 1. 雷公藤 :ti,ab,kw \\
\hline & 2. 雷公藤多式 :ti,ab,kw \\
\hline & 3. 雷公藤多苷: $t i, a b, k w$ \\
\hline & 4. 1 or 2 or 3 \\
\hline & 5. 干燥综合征 :ti,ab,kw \\
\hline & 6. 4 and 5 \\
\hline
\end{tabular}


Table S3 Participants, intervention, comparison, outcome, and study design criteria (PICOS) for inclusion and exclusion of studies

\begin{tabular}{ll}
\hline Items & Descriptions \\
\hline Participants & Patients diagnosed with Sjögren's syndrome \\
Intervention & Tripterygium glycosides alone or combined therapies \\
Comparison & Control groups of conventional therapies \\
Outcomes & Efficacy rate, symptom scores, serum index, physical index, adverse events \\
Study design & Randomized controlled trials \\
\hline
\end{tabular}

